\title{
Effects of Calendering on Print Densities of Coated Paperboards
}

\author{
Sinan SÖNMEZ \\ University of Marmara, School of Applied Sciences, Department of Printing Technologies
}

\begin{abstract}
In this study, the effect of calendering on print quality was determined. For this purpose, five different pigment-coating formulations were prepared. They were coated on the surface of the base paperboard, previously coated with starch. Half of the coated base paperboards were calendered. Then, the Ugra82 (Ugra82 Plate Control Wedge) was printed on calendered and uncalendered-coated base paperboard surface by offset printing using black inks. All solid density measurements on the printed wedge were performed using a calibrated Gretag Macbeth Spectrolino Spectrophotometer. Double coating of the base paperboard surface is important for printability. As a result of measurement, it was found that calendering increased the surface smoothness. The surface smoothness of coated paperboard increased as long as ink absorption reduced. Hence, density value augmented after calendering. Generally, the raise of the kaolin ratio in the coating formulations affected positively printability.
\end{abstract}

Keywords: Paperboard, Coating, Pigment, Calendering, Printing

\section{INTRODUCTION}

Whether paperboard packages have good printability surfaces they will have resistance against moisture, oil and air affects. Not only the paperboard packages protect their contents from environmental effects, but also they must have good printability increasing visual appeal [1]. Printability is affected by the physical properties of the paperboard as well as the relationship between the paperboard, ink and the printing machine. It is also important that the source of light is as near as possible in color to natural light $[2,3]$.

A good print will have high print gloss, extended tone range, minimal oil absorption, and optimal print density. These properties will be affected by substrate properties; roughness, porosity, brightness and opacity [3]. An increase in surface roughness influences the optical properties of the surface leading to a reduction of intensity in the secular's direction and an increase in diffuse direction. [4]. Paper surface roughness values effect the dot-gain values.

The substrate consists of a pigment coating inter layer, which is coated on top of a barrier latex layer. The pigment coating inter layer controls the absorption of ink solvents [5]. The type, size, and shape of pigment particles as well as binder combinations in coatings are all important factors for ink absorption [6].
Ink penetration through a coated paper is not a desirable feature of a sheet-fed or heat-set offset printed product. Adhesion of the ink on the surface of the substrate allows a higher density for the same amount of ink applied. This is obviously more cost effective and also can result in a brighter cleaner print [7].

\section{MATERIAL AND METHOD}

The base paperboard coated with starch was supplied from the paperboard manufacturer. Roughness properties of samples were measured according to TAPPI T555-om-99. Gloss values of samples were measured at $75^{\circ}$ using a Novo-Gloss ${ }^{\text {TM }}$ Glossmeter based on TAPPI T480-om-99. Cobb values of samples were tested by means of TAPPI T441 om - 90. CIE Whiteness, Brightness and Yellowness properties of samples were measured based on TAPPI T1216 sp-98. Three different pigments (Table 1) were utilized on the second and third layers whereas the binder (Table 2) and additives remained constant throughout the study. The third layers were coated using five different coating formulations (Table 3). However, the second layer pigment formulation was not varied throughout the study. 


\section{II.1. Coating Formulations and Application Methods}

For this study, six different coatings were prepared with pigments of different aspect ratios and binders. The coating formulations applied are given in Table 3. All coatings were prepared by the ratios of $60 \%$ solids. The $\mathrm{pH}$ of the coatings were not adjusted and in the $\mathrm{pH}$ range of 8 to 9. After mixing for 30 minutes, $\mathrm{pH}$ (ISO 6588:1981), percentage coating solids (ISO 638:1978), and viscosity (TAPPI T666 om - 91) were measured. The viscosities of the coatings were gauged with a Brookfield viscometer (spindle No. 2; measuring speed $100 \mathrm{rpm}$ ). Coatings were introduced using a K- Control laboratory coater. The coatings were carried out at two coat weights by use of two different rods and air dried overnight according to TAPPI T402. After the coating process, the coated test liner samples were calendered at 300 PLI, 2-nips against a polished metal roll.
While the solids ratio of the second white layer formulation was $60 \%$, the third white layer formulation's was $62 \%$. The viscosity values were $300 \pm 100 \mathrm{cP}$ (centipoises) and $\mathrm{pH}$ was 8.5 . The pigment coating was applied to the base paperboard surface using a K Control Coater and its bars.

After the coated base paperboards dried out, they were calendered. Calendering process continued until the coated base paperboards had enough brightness. Temperature and pressure of the calendering process was kept constant throughout the period of the study.

The Ugra82 was printed on the calendered and uncalendared-coated paperboards using offset printing with black inks and a plate prepared at $60 \mathrm{lpc}$. Print densities were measured using a calibrated Gretag Macbeth Spectrolino Spectrophotometer (D50, 2 degree observer, UV included, with white backup) according to ISO 12647-2.

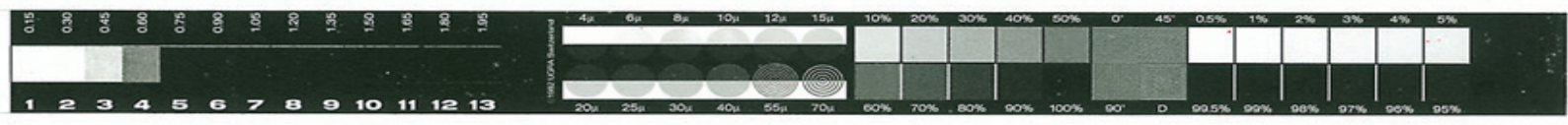

Image 1: Ugra82 Plate Control Wedge

\section{RESULTS AND DISCUSSIONS}

Luminosity, grain size and $\mathrm{pH}$ values of pigments utilized in operational tests are given in Table 1. Table 2 shows binder properties. Coating formulations are given in Table 3. In Tables 4 and 5, optical and physical properties of uncalendered and calendered-coated paperboards are presented.

Table 1: The characteristics of the mineral pigments

\begin{tabular}{|l|l|l|l|}
\hline Pigments & Brightness & Particle size & pH \\
\hline Kaolin & $88 \%$ & $80 \%(2 \mathrm{~mm}$ below $)$ & $6-8$ \\
\hline Calcium carbonate & $93 \%$ & $56 \%(2 \mathrm{~mm}$ below $)$ & 9.50 \\
\hline Titanium dioxide & $95 \%$ & $0.25-0.35 \mathrm{~mm}$ & $6-8$ \\
\hline
\end{tabular}

Table 2: The characteristics of the binders (Latex)

\begin{tabular}{|l|l|}
\hline Properties & Amount \\
\hline Dry matter & $50 \% \pm 1$ \\
\hline Viscosity & $370 \mathrm{mPa} . \mathrm{s}$ \\
\hline Density & $1,02 \mathrm{~g} / \mathrm{cm}^{3}$ \\
\hline $\mathrm{pH}$ & $8 \pm 0.50$ \\
\hline
\end{tabular}

Table 3: Using pigments and binder parts to the formulations

\begin{tabular}{|l|l|l|l|l|l|}
\hline Pigments & F1 & F2 & F3 & F4 & F5 \\
\hline Kaolin & 50 & 25 & 75 & 30 & 30 \\
\hline Calcium carbonate (Calcite) & 50 & 75 & 25 & 65 & 60 \\
\hline Titanium dioxide & - & - & - & 5 & 10 \\
\hline Binder (Latex) & 8 & 8 & 8 & 8 & 8 \\
\hline
\end{tabular}

Table 4: The physical properties of uncalendared base paperboard

\begin{tabular}{|l|l|l|l|l|l|}
\hline Testing & F1 & F2 & F3 & F4 & F5 \\
\hline Cobb $\left(\mathbf{g} / \mathbf{m}^{2}\right)$ & 101 & 100 & 97 & 107 & 104 \\
\hline Gloss $\mathbf{7 5}^{\circ} \mathbf{( \% )}$ & 35 & 24 & 40 & 31 & 28 \\
\hline Roughness (microns) & 3.78 & 3.66 & 3.14 & 3.17 & 3.32 \\
\hline Brightness (\%) & 78.20 & 79.00 & 77.60 & 79.70 & 81.40 \\
\hline Yellowness (\%) & 0.47 & 0.10 & 0.70 & 0.40 & 0.42 \\
\hline CIE Whiteness (\%) & 90 & 95 & 86 & 81 & 81 \\
\hline
\end{tabular}


Table 5: The physical properties of calendared base paperboard

\begin{tabular}{|l|l|l|l|l|l|}
\hline Testing & F1 & F2 & F3 & F4 & F5 \\
\hline Cobb (g/m $\left.\mathbf{m}^{2}\right)$ & 95 & 94 & 70 & 92 & 98 \\
\hline Gloss $\mathbf{7 5}^{\circ} \mathbf{( \% )}$ & 44 & 37 & 54 & 40 & 42 \\
\hline Roughness (microns) & 2.04 & 2.09 & 1.73 & 1.88 & 1.67 \\
\hline Brightness (\%) & 77.40 & 78.30 & 77.10 & 79.60 & 81.30 \\
\hline Yellowness (\%) & 0.60 & 0.22 & 0.80 & 0.42 & 0.48 \\
\hline CIE Whiteness (\%) & 87.70 & 91.80 & 85.40 & 82.00 & 81.80 \\
\hline
\end{tabular}

After the calendering process, cobb values decreased. The lowest Cobb value was gathered from F3, which contained 100 parts Kaolin. However, The F3 had the highest gloss value. The increase of the Kaolin [8] in the coating formulations led to an augmentation in the yellowness value. However, it resulted in the highest brightness values. The highest brightness value was obtained in the case of F5, containing 10 parts titanium dioxide. The smoothness values improved after the calendering process. The kaolin addition caused a raise in the smoothness due to the particle shape (Table 4, 5).
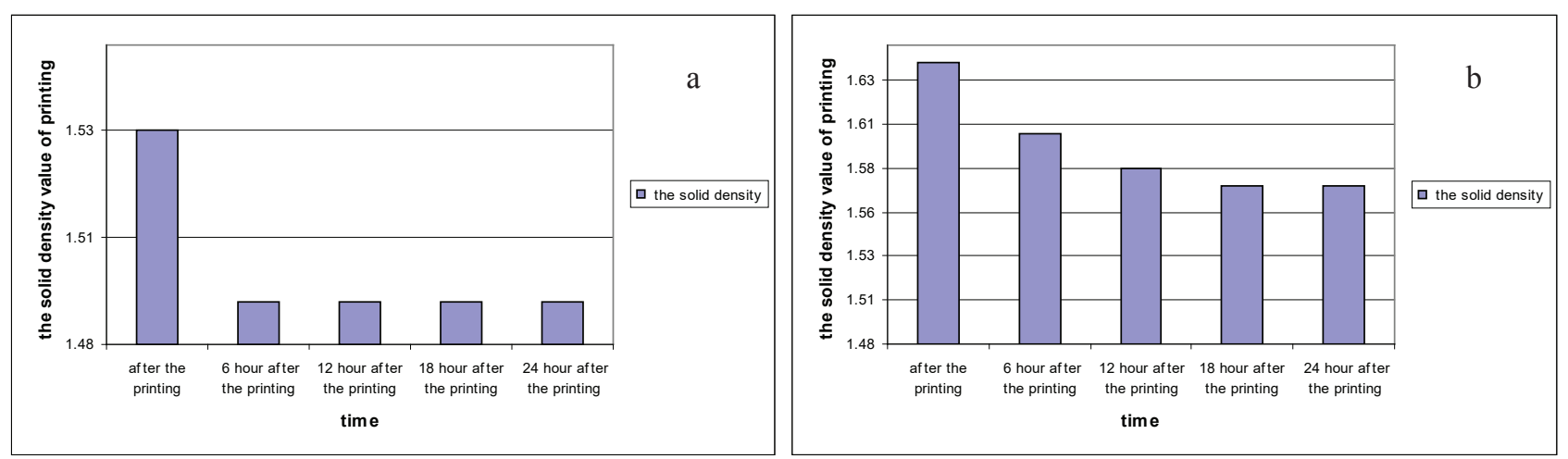

Figure 1: Formula 1-The solid density values of black printing (a) uncalendered and (b) calendered paperboards

F2 was comprised of 25 parts Kaolin and 75 parts Calcium carbonate. It was derived from the results that when kaolin part in formulation decreased, the density value of printed uncalendered paperboard increased. However, density value of printed calendered paperboard did not effect this change (Figure 2). 

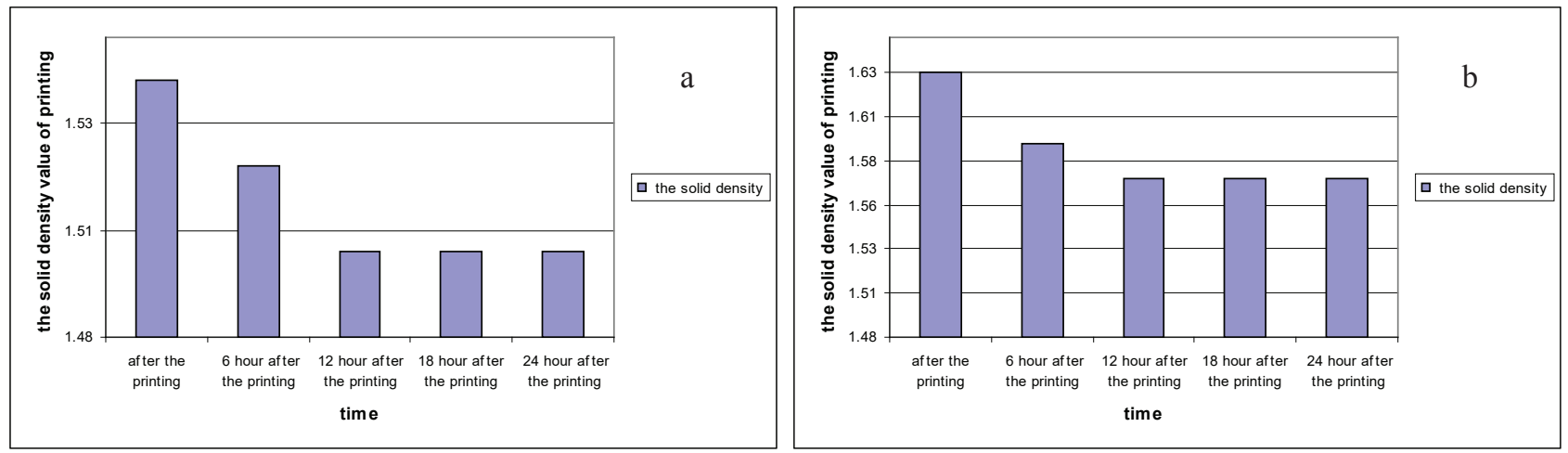

Figure 2: Formula 2 -The solid density values of black printing (a) uncalendered and (b) calendered paperboards

F3 included 75 parts Kaolin and 25 parts Calcium carbonate. Here the raise in uncalendered paperboard density value depending on the amount of kaolin was more evident than F2's. Indeed, the density value of F3 was higher than F4 and F5, containing the titanium dioxide.
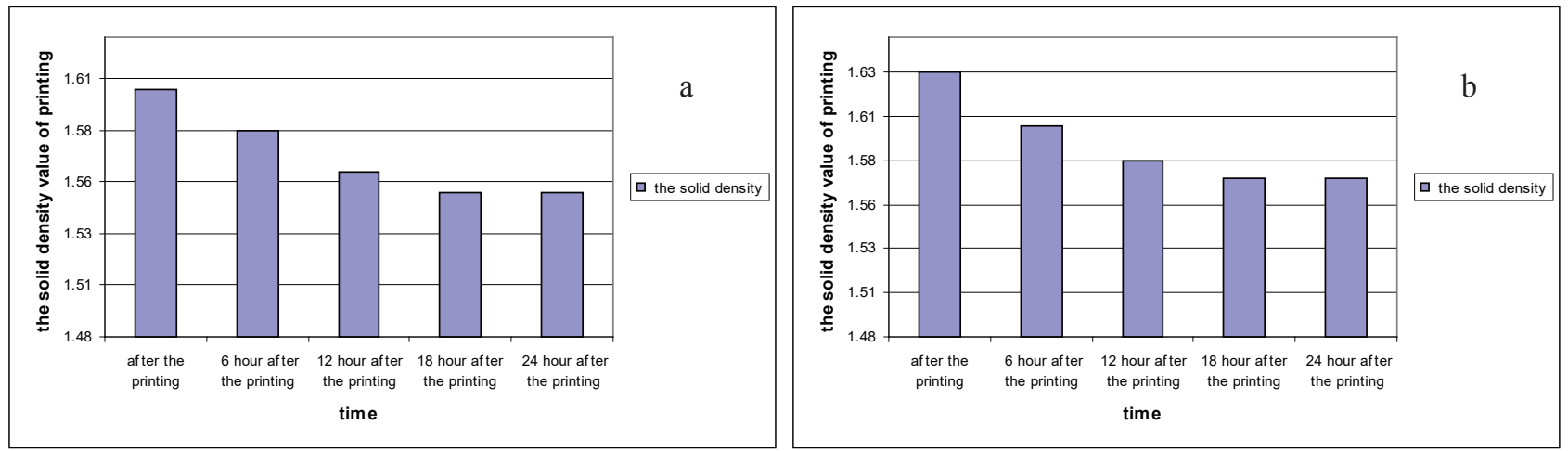

Figure 3: Formula 3 -The solid density values of black printing (a) uncalendered and (b) calendered paperboards

F4 was consisted of 30 parts Kaolin, 65 parts Calcium carbonate and 5 parts Titanium dioxide. The titanium dioxide use reduced the amount of the kaolin utilization, thus diminished the density value both uncalendered and calendered paperboard. However, the density loss at 6 hour after the printing was minor comparing to the titanium dioxide-free formulae.
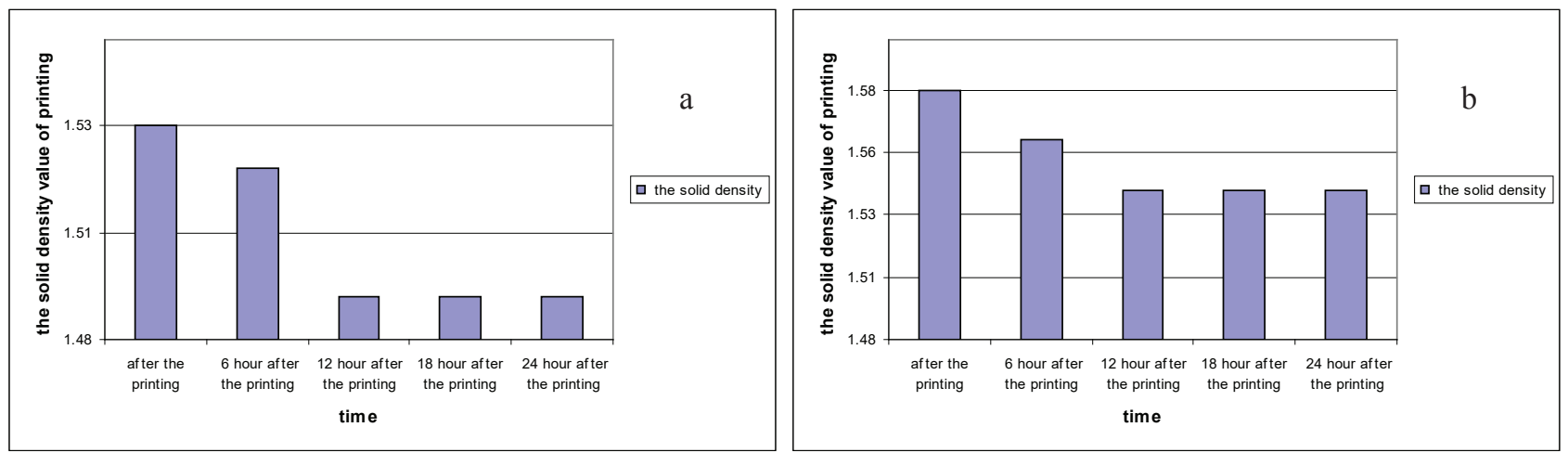

Figure 4: Formula 4 -The solid density values of black printing (a) uncalendered and (b) calendered paperboards 
F5 incorporated 30 parts Kaolin, 60 parts Calcium carbonate and 10 parts Titanium dioxide. The increase of titanium dioxide in formula led to the raise of density values of both uncalendered and calendered ones. Therefore, the density value of the calendered one was lesser than the titanium dioxide-free formulations.
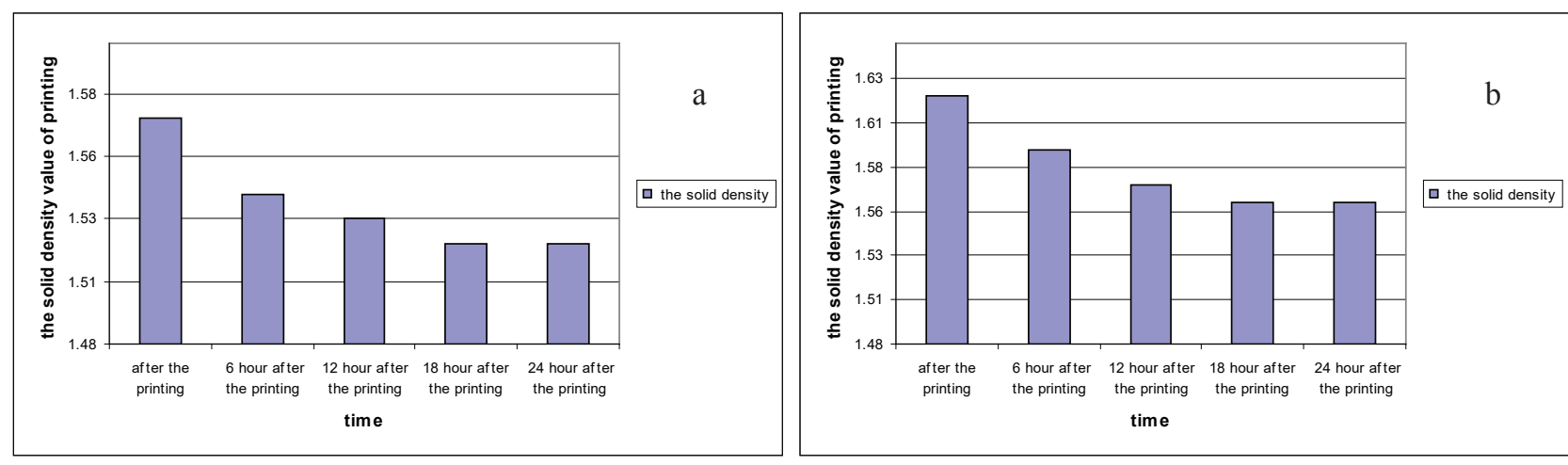

Figure 5: Formula 5-The solid density values of black printing (a) uncalendered and (b) calendered paperboards

SEM images of pigments in the formulations at x15000 magnification are shown on Images 2-4.

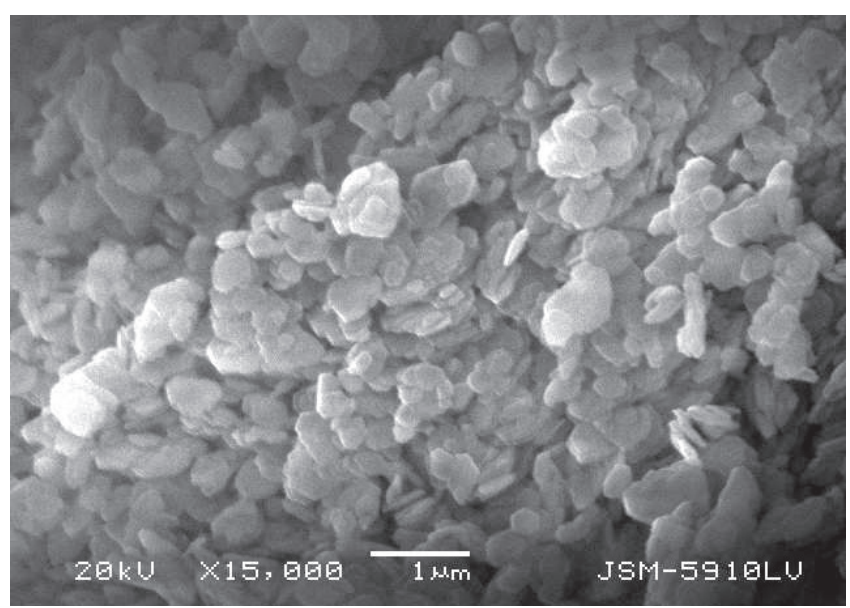

Image 2: The SEM image of Kaolin pigments

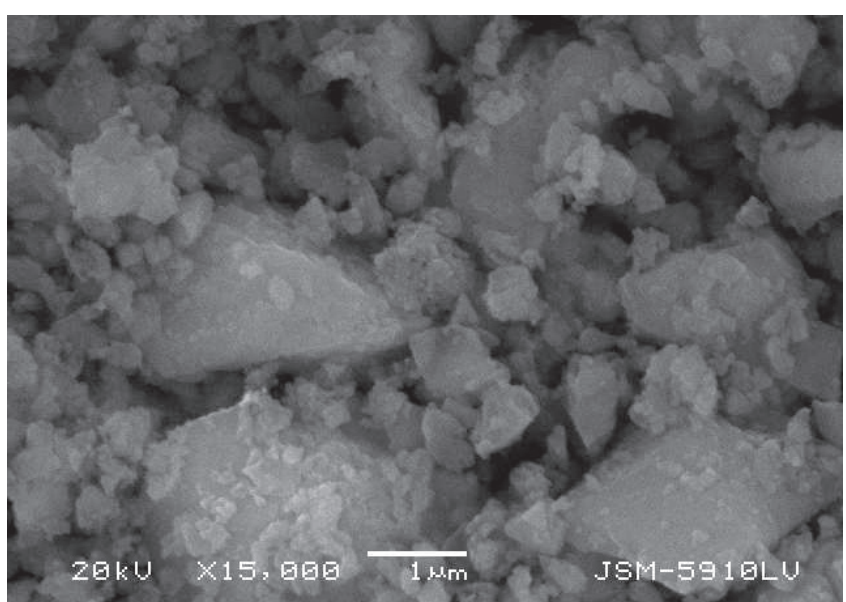

Image 3: The SEM image of Calcium carbonate pigments

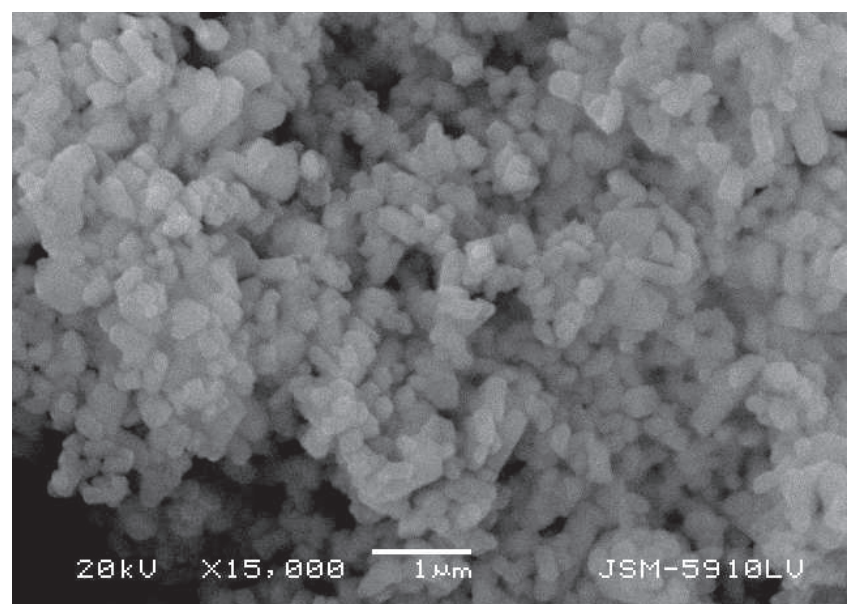

Image 4: The SEM image of Titanium dioxide pigments 


\section{Conclusions}

The solid density values on the calendered-coated base paperboards were higher than those of uncalendered-coated base paperboards according to the results obtained from density measurements of the Ugra 82. The higher densities revealed a heavier ink film layer on the substrates, which have a low roughness value. The augmentation of kaolin pigment in formulations increased the print density due to the plate shaped particles, also causing the raise in the smoothness values.

Calendering reduced the ink absorption due to the improved surface smoothness of coated paperboard. Thus, after calendaring the density values got better.

Coating formulations combining the calcium carbonate pigment and kaolin pigment can be utilized in order to diminish the ink absorption by decreasing the solid print density.

Calcium carbonate pigments developed the brightness and CIE whiteness values of the coated paperboards. The calcium carbonate pigments structure comprised of small prisms led to high roughness values. The ratio of the absorption was grown due the increased capillary spaces.

Although, the use of high ratio titanium dioxide pigments in formulation advanced the print density, the density values acquired via this formula were lesser than the titanium dioxide-free ones.

As a result, when the ratio of calcium carbonate is augmented in the formulation, the brightness and CIE whiteness values were risen. But, the solid density value was reduced. Hereby, it was concluded that the ratio of kaolin in the formulation should be kept high.

\section{References}

[1] Koivula, H., Preston, J.S., Heard, P.J. and Toivakka, M. (2004). Visualisation of the distribution of offset ink components printed onto coated paper. Colloids and Surfaces A: Physicochemical and Engineering Aspects, 244 (1-3), 67-71.
[2] Klass, C.P. (2004). Paperboard as Coating Base Stock. Klas Associates Inc., Radnor, PA, p. 1, 9-10.

[3] Joukio, R., Mansikkamäki, S. (1998). Paper and Paperboard Converting, Chapter 8. Carton board Package Manufacturing and Applications, Published in Cooperation with The Finnish Paper Engineers' Association and TAPPI, Jyväskylä, Finland, p. 215-241.

[4] Oittinen, P., Saarelma, H. (1998). Printing, Chapter 9. Published in Cooperation with The Finnish Paper Engineers' Association and TAPPI, Jyväskylä, Finland, p. 231-232.

[5] Tåg, C.M., Pykönen, M., Rosenholm, J.B. and Backfolk, K. (2009). Wettability of model fountain solutions: The influence on topo-chemical and -physical properties of offset paper. Journal of Colloid and Interface Science, 330 (2), 428436.

[6] Elmas, G.M., Sonmez, S. (2011). Printability properties of some ASAM Handsheets. Asian Journal of Chemistry, 23 (6), 2515-2519.

[7] Sonmez, S. (2011). Interactive Effects of Copolymers and Nano-sized Pigments on Coated Recycled Paperboards in Flexographic Print Applications. Asian Journal of Chemistry, 23(6), 2609-2613.

[8] Silva, F.A.N.G., Luz, A.B., Sampaio, J.A., Bertolino, L.C., Bernstein, S.R., Duttine, M, and Silva, F.T. (2009). Technological characterization of kaolin: Study of the case of the Borborema-Seridó region (Brazil). Applied Clay Science, 44 (3-4), 189-193.

[9] Arnold, M. (1997). Ground Calcium carbonate in Coated Papers and Board. OMYA Plüss-Staufer AG, Oftringen, Switserland, p. 2-3, 5.

[10] Naydowski, C. (1995). Properties of Calcium Carbonate Pigments. Senior Vice President, R \& D Technical Service, Plüss-Staufer AG, Oftringen, Switserland, p.1-10.

[11] Kralj, J.K.D., Breèeviæ, L. and Falini, G. (2008). Influence of some polysaccharides on the production of calcium carbonate fillerparticles. Journal of Crystal Growth, 310(21), 4554-4560. 